\title{
Effect of Thermal Treatment and Relative Humidity on The d-spacings of Poly(ethylene glycol) Montmorillonite Nanocomposites
}

\author{
Khairuddin \\ Jurusan Fisika FMIPA, Universitas Sebelas Maret \\ Surakarta,57126, INDONESIA \\ Email:khairuddin@uns.ac.id
}

\begin{abstract}
The effect of temperature and relative humidity on the d-spacing of montmorillonite (MMT) clay in Poly(ethylene glycol) Mw 600 (PEG600) nanocomposites prepared by solution casting has been investigated, since it can be significantly affected by any associated water. X-ray diffraction (XRD) traces were collected from samples after heating for 10 minutes at $80{ }^{\circ} \mathrm{C}$ and $150{ }^{\circ} \mathrm{C}$ and then after cooling and equilibrating for 24 hours at $20{ }^{\circ} \mathrm{C}$ and $50 \%$ $\mathrm{RH}$, the samples were then equilibrated for 24 hours at $20^{\circ} \mathrm{C}$ and $85 \%$ relative humidity. It was found that below a loading of $4 \mathrm{wt} \%$ PEG600 the d-spacing collapses upon heating at $150{ }^{\circ} \mathrm{C}$, that by $13 \mathrm{wt} \%$ PEG600 a fully loaded single layer is formed, while by $17 \mathrm{wt} \%$ PEG600 a bilayer is formed. Above $17 \mathrm{wt} \%$ PEG600, the spacing was not affected by thermal treatment and relative humidity indicating that clay gallery was fully loaded by PEG600 and or very small water molecules associated with PEG600 in the MMT gallery.
\end{abstract}

Keywords: Poly(ethylene glycol), montmorillonite, d-spacing, thermal treatment, relative humidity, $\mathrm{x}$-ray diffraction.

\section{Introduction}

Polymer clay nanocomposites have attracted great attention in the last decade since they simultaneously impart significant improvements in mechanical, barrier and fire retardant properties when compared with those of the pure polymer ${ }^{1,2}$. It is well known that the addition of as little as $5 \mathrm{wt} \%$ clay can give the same level of mechanical and thermal improvement as those typically achieved with loadings of 20-40 wt $\%$ of micron size fillers such as glass fibre, talc, calcium carbonate or carbon black ${ }^{3}$.

Poly(etehyelene glycol) (PEG) is of interest since over the past decade as it has been used as pharmaceuticals compositions, as a food additive, and as plasticizer ${ }^{4}$. When it mixes with clay to form PEGclay composite, it is used as water based drilling fluids if clay is the major phase and as rechargeable batteries in which polymer is the continuous phase ${ }^{5}$.

When clay is dispersed in polymer matrix, two major types of nanocomposites; intercalated and exfoliated can often be found in different regions of a nanocomposite material ${ }^{6}$. For ordered-intercalated systems, the spacing between individual clay layers, called the d-spacing, increases from its intrinsic value as polymer chains or monomer molecules diffuse into the clay galleries. Such intercalated nanocomposites show diffraction peaks in their XRD patterns. In exfoliated systems the individual clay layers are separated from the intercalated tactoids and are dispersed in the matrix polymer with no apparent inter-particle interactions. The exfoliated nanocomposites do not show any XRD diffraction peaks that could be attributed to ordered clay layers ${ }^{7}$.

As montmorillonite clay and poly(ethyelene glycol) are hydrophilic, the d-spacings can increase greatly when they are associated with water. Hence, the aim of this study is to assess the present of water in the clay gallery of PEG montmorillonite nanocomposites. 


\section{Sample Preparation}

The clay sample was sodium montmorillonite (MMT) supplied by Southern Clay Products with the tradename Cloisite $\mathrm{Na}^{+}$and has a CEC $=92.5 \mathrm{meq} / 100 \mathrm{~g}$, and PEG $(M w$ 600) was obtained from Aldrich. The nanocomposites were prepared by solution casting. One $\mathrm{g}$ of MMT was dispersed in $14 \mathrm{ml}$ of deionised water in a glass container at room temperature by stirring with a magnetic/heater stirrer. The desired amount of PEG was mixed with $6 \mathrm{ml}$ deionised water also at room temperature. MMT suspension and PEG solution were then mixed and stirred for a further 4 hours at room temperature before casting a $2 \mathrm{ml}$ aliquot on to a glass slide and $18 \mathrm{ml}$ suspension into a Petri dish. All the suspensions were dried in an oven at $40{ }^{\circ} \mathrm{C}$ for 24 hours before being exposed to thermal treatment and relative humidity, and analysed by X-ray diffraction (XRD).

XRD traces were collected from samples after heating for 10 minutes at $80{ }^{\circ} \mathrm{C}$ and $150{ }^{\circ} \mathrm{C}$ and then after cooling and equilibrating for 24 hours at $20{ }^{\circ} \mathrm{C}$ and $50 \% \mathrm{RH}$, the samples were then equilibrated for 24 hours at $20^{\circ} \mathrm{C}$ and $85 \%$ relative humidity. Note that any degradation to the clay or PEG is unlikely to occur at these temperatures. The relative humidities of $50 \%$ and $85 \%$ were achieved by placing saturated magnesium nitrate and potassium chloride salt solution, respectively in a humidity chamber ${ }^{8}$.

All XRD measurements conducted in this report used $\mathrm{CuK}_{\alpha 1}$ as the source of X-rays (1.54186 $\AA$ ) at 40 $\mathrm{mA}$ and $40 \mathrm{kV}$. A divergent slit of $0.5^{\circ}$, anti scatter slit of $1^{\circ}$, and mask of 15 were used. Data was collected using step size of $0.02^{\circ}$ and a scan time of $1 \mathrm{~s}$ per step.

\section{Result and discussion}

A wide range of MMT loadings (5 to 95 wt \%) into PEG600 have been investigated, their XRD traces are presented in Figures 1 and 2, which show intercalated structures for the whole range of MMT loadings. Three steps are observed as the concentration of PEG600 increases, a depleted single layer $\left(<6.64^{\circ} 2 \theta\left(\mathrm{d}_{001}<\right.\right.$ $13.31 \AA$ ) $)$ ) to a fully loaded single layer $\left(6.4^{\circ} 2 \theta, \mathrm{d}_{001}<\right.$ $13.81 \AA$ ) $)$ and then a bilayer structure $\left(4.97^{\circ} 2 \theta, \mathrm{d}_{001}<\right.$ $17.78 \AA$ Á).

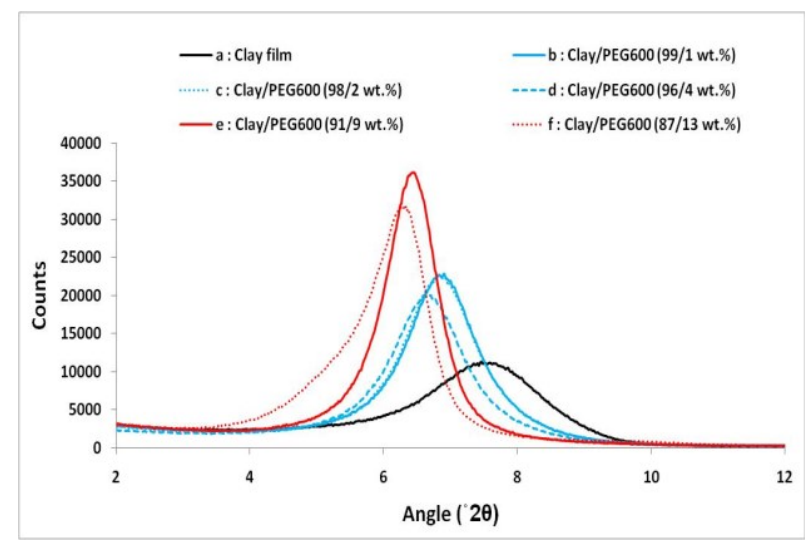

Figure 1. XRD traces for PEG600/MMT nanocomposites at low PEG600 content

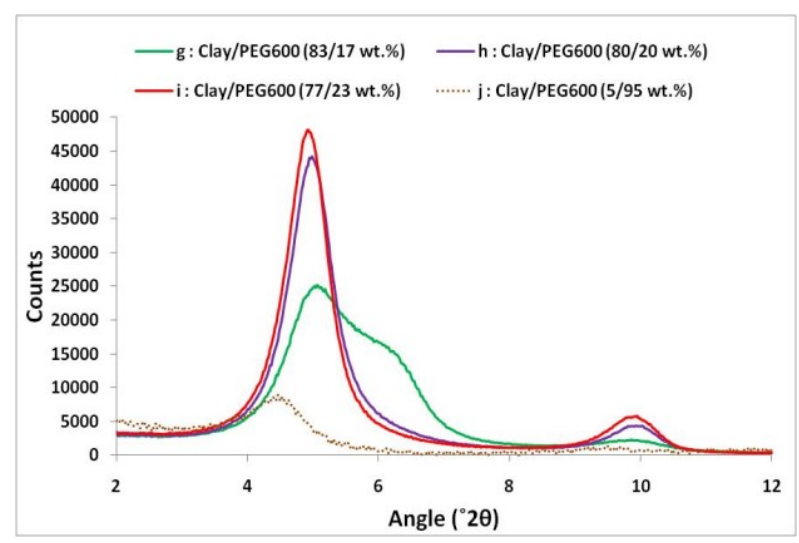

Figure 2. XRD traces for PEG600/MMT nanocomposites at low PEG600 content.

Even small amounts of PEG600 (1 wt \%) increase the d-spacing of the MMT gallery (see Figure 1). However, the MMT layers do not expand to a fully loaded single layer at $4 \mathrm{wt} \%$ PEG600 in which the peak position is at $6.64{ }^{\circ} 2 \theta(13.31 \AA$ ) $)$. Once a fully loaded single layer is achieved at 9 wt \% PEG600, the peak position is at $6.40{ }^{\circ} 2 \theta$ (13.8 $\AA$ ), further loading of PEG600 (13 wt \%) results in a portion of bilayer structures together with the single layer as the dominant phase. A mixture of single and bilayer structures are clearly observed at a PEG600 loading of $17 \mathrm{wt} \%$ (see Figure 2) since there are two peaks positioned at 6.17 ${ }^{\circ} 2 \theta\left(14.3 \AA\right.$ \&́) and $5.0{ }^{\circ} 2 \theta(17.4 \AA$ ) $)$, at this stage the peak representing the bilayer structure is more intense than that of the single layer. The bilayer becomes fully loaded when the PEG600 loading is at $20 \mathrm{wt} \%$, as evidenced by a narrow distribution of $\mathrm{d}$-spacings and the high intensity of the peak at $4.97{ }^{\circ} 2 \theta$ (17.78 $\AA$ ). Further loadings of PEG600 up to 95 wt \% results in a 
slight peak shift to $4.43^{\circ} 2 \theta(19.94 \AA$ Á), this shows the MMT layers don't continue to expand unlike when the MMT was dispersed in PVOH. The non-expansion indicates a strong PEG600-MMT interaction.

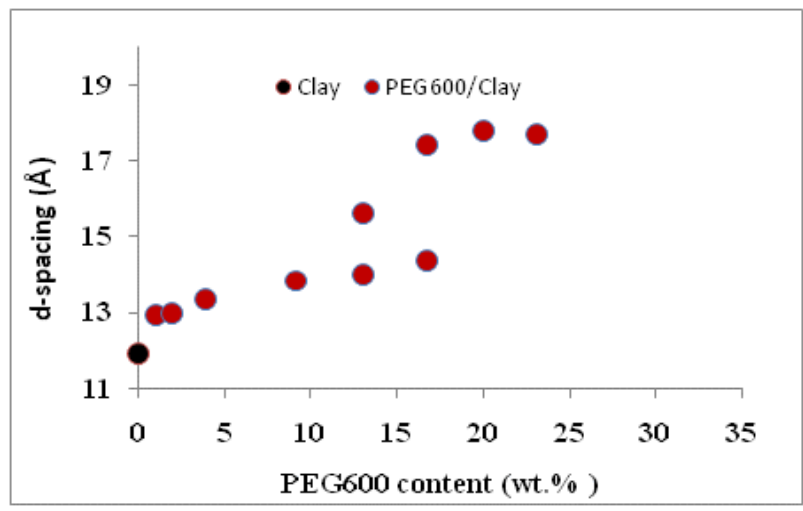

Figure 3. A summary of d-spacing observed in the XRD traces of PEG600/MMT nanocomposites

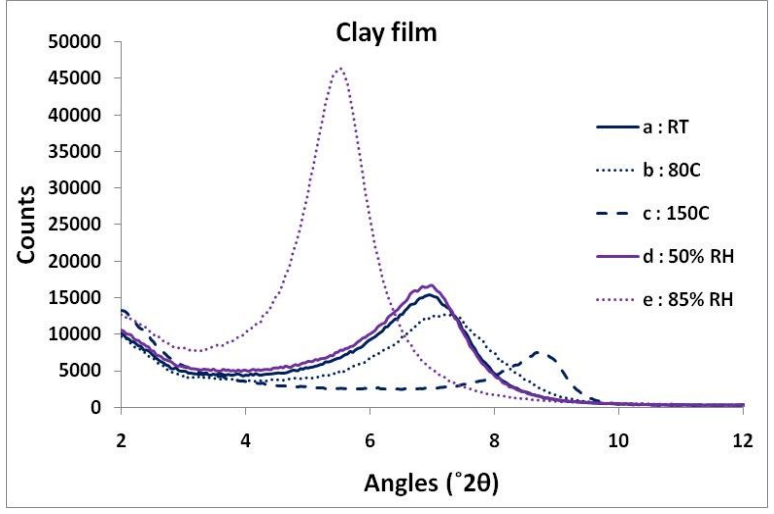

Figure 4. The influence of thermal treatment and relative humidity on the diffraction patterns of MMT clay

The $\mathrm{d}_{001}$-spacings observed in the XRD traces of the PEG600 and MMT nanocomposites are plotted in Figure 2 and shows that PEG600 resides in the gallery and forms only intercalated nanocomposites. As the concentration of PEG600 increases, step changes occur as the gallery expands from a depleted single layer to a fully loaded single layer and then a bilayer structure. A maximum d-spacing of $\approx 18.2 \AA$ for PEG in MMT was also reported by Chen ${ }^{9}$ who studied PEG's with Mw's 300-20,000.

Figure 4 shows XRD traces of MMT film collected at variable temperatures and humidities. RT represents when the experiment was conducted at room temperature, i.e. $\sim 20{ }^{\circ} \mathrm{C}$ after initially casting the film at
$40{ }^{\circ} \mathrm{C}$ and atmospheric humidity, $\sim 15-50 \% \mathrm{RH}$. After heating the MMT film at $80{ }^{\circ} \mathrm{C}$, a slight shift to higher angle was observed, but this was more significant when heated to $150{ }^{\circ} \mathrm{C}$ were the MMT layers had collapsed from $7^{\circ} 2 \theta(12.63 \AA \dot{A})$ at room temperature to $9.2^{\circ} 2 \theta$ (9.6 ̊́) at which point very limited or even no water is present in the MMT gallery due to adsorbed moisture and interlayer water being expelled from the MMT. Further investigation of the sample showed a reversible process where the sample was able to rehydrate at $50 \%$ RH showing a very similar trace to the original trace collected at RT. Also, the MMT sample was able to swell further at higher humidities $(85 \% \mathrm{RH})$ indicated by a shift in the peak to lower angles $\left(5.8^{\circ} 2 \theta / 15 \AA\right.$ ). Increasing the amount of water available to the sample increased the peak intensity and narrowed the peak width indicating a more ordered system. Chen ${ }^{10}$ found that when heating to $600{ }^{\circ} \mathrm{C}$ the $\mathrm{d}$-spacing also collapsed to $9.6 \AA$ and did not alter further when heated to $800^{\circ} \mathrm{C}$. They also reported that rapid loss of hydroxyls and slight distortion of the tetrahedral silica structure began at about $600{ }^{\circ} \mathrm{C}$ as shown by the disappearance of the absorption band at $3620 \mathrm{~cm}^{-1}$ and a slight shift to higher wavenumbers for the $\mathrm{Si}-\mathrm{O}$ absorption peak at $998 \mathrm{~cm}^{-1}$ in the FTIR measurements.

The XRD trace of PEG600/MMT nanocomposites after being exposed to thermal and relative humidity's is given in Figure 5a. It shows that the XRD trace collected at $150^{\circ} \mathrm{C}$ from the MMT with $1 \mathrm{wt} \%$ PEG600 (Figure 5) is very similar to that of the base MMT (Figure 4). The MMT gallery has collapsed suggesting there is very little, if any, PEG600 present in the gallery. The corresponding trace for the MMT sample treated with 4 wt \% PEG600 and collected at $150{ }^{\circ} \mathrm{C}$, does exhibit a peak at $6.78{ }^{\circ} 2 \theta(13.04 \AA$ ) $)$ indicating the present of PEG600 in the gallery. Heating the sample treated with 9 wt $\%$ PEG600 to $80{ }^{\circ} \mathrm{C}$ or $150{ }^{\circ} \mathrm{C}$ does not displace the peak at $6.78{ }^{\circ} 2 \theta$ nor diminish its intensity which shows that the gallery contains little water and enough PEG600 to create a fully loaded single layer. Increasing the amount of water available to the samples with 1 to $9 \mathrm{wt} \%$ PEG600 by exposing them to higher humidity $(85 \%)$ results in the peak position shifting to higher spacing at $5.7^{\circ} 2 \theta(15.31 \AA \AA)$. Here, the gallery has swollen with water to a spacing similar to that of a fully loaded bilayer. 

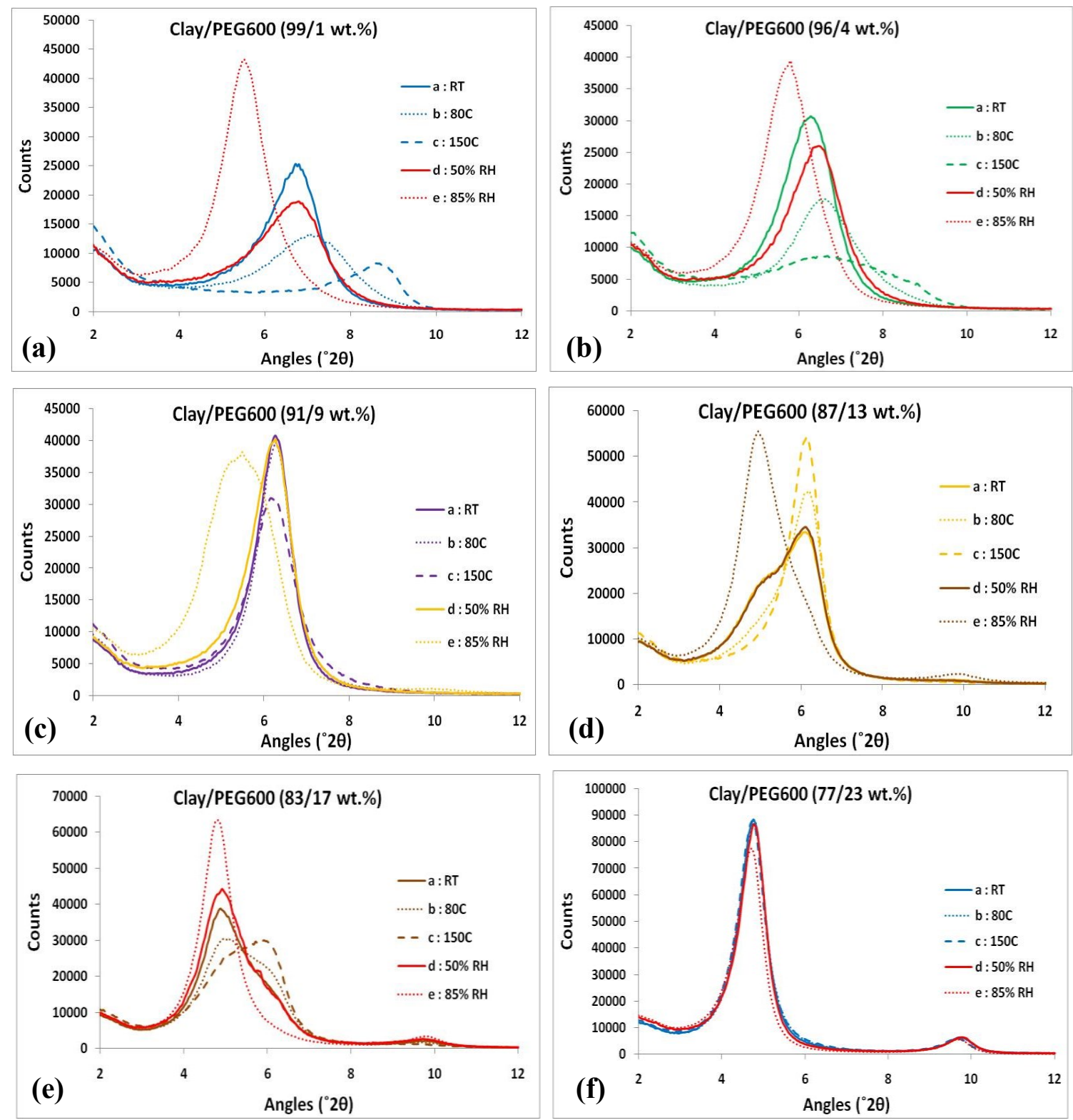

Figure 5. The influence of thermal treatment and relative humidity on the diffraction patterns of PEG600/MMT nanocompistes

Heating the samples which have both a single and double layer (13 wt \% and 17 wt \% PEG600) sees the intensity of the double layer decrease suggesting the double layer structure is not yet fully loaded. Conversely, increasing the amount of water available to the sample reduces the intensity of the single layer and increases the intensity of the bilayer. The bilayered structure created by treating the MMT with 17 wt \% PEG600 has better thermal stability than that with $13 \mathrm{wt}$ $\%$ PEG600.
The changes in d-spacings observed in the MMT/PEG600 samples under the influence of temperature and rehydration are plotted in Figure 6. It is clear that below a loading of 4 wt \% PEG600 the dspacing collapses upon heating at $150^{\circ} \mathrm{C}$, that by $13 \mathrm{wt}$ $\%$ PEG600 a fully loaded single layer is formed, while by $17 \mathrm{wt} \%$ PEG600 a bilayer is formed. Above $17 \mathrm{wt}$ $\%$ PEG600, the spacing was constant probably due to MMT gallery was fully loaded by PEG600 and or very small water molecules entering the gallery. 


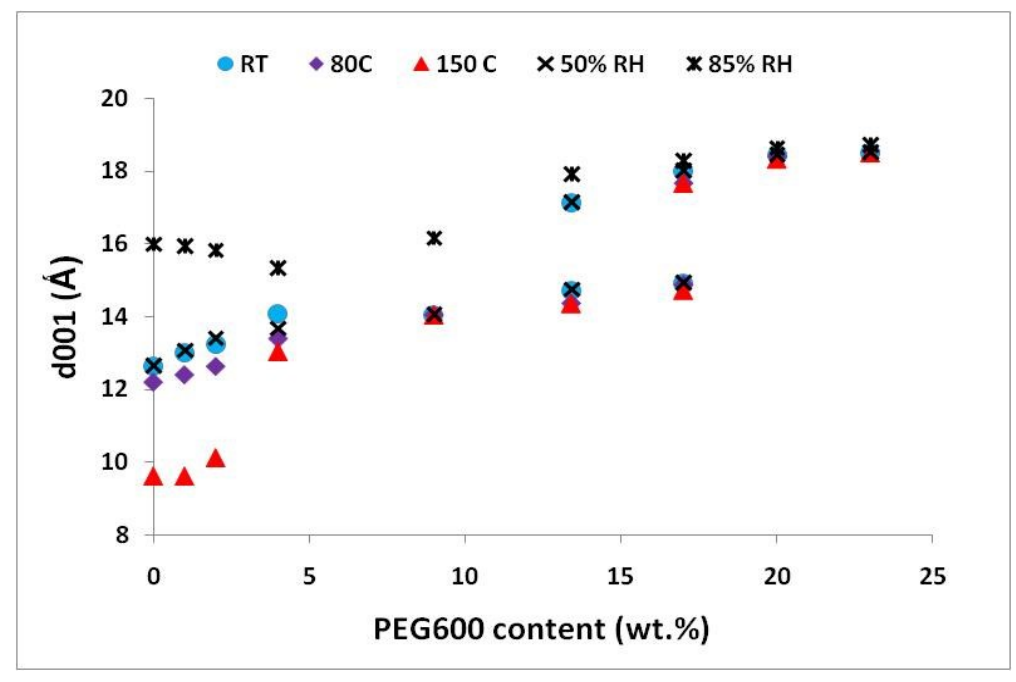

Figure 6. A summary of d-spacing of PEG600 MMT nanocomposites under the influence of thermal treatment and relative humidity

\section{Conclusion}

It is found that structure of $\mathrm{PEG} /$ montmorillonite nanocomposites was intertercalated. Three steps can be used to describe the changes as the concentration of PEG600 increases: first; an increase to a depleted single layer at $\sim 6.64^{\circ} 2 \theta(\sim 13.1 \AA$ ) $)$, second; a depleted single layer to a fully loaded single layer at $\sim 6.4^{\circ} 2 \theta(\sim 13.8$ $\AA$ ), third; fully loaded single layer to a bilayer structure at $\sim 4.97^{\circ} 2 \theta(\sim 17.8 \AA$ \&́). The water associated with PEG600 in the MMT gallery was depend on the relative humidity and depressed as PEG600 loading was increased. The gallery space was fully inhibited by PEG600 when the PEG600 loading was above $17 \mathrm{wt} \%$.

\section{Acknowledgements}

For the financial assistance from the Indonesian Government (DIKTI Scholarship) throughSebelasMaret University, Surakarta, Central Java, Indonesia.

\section{References}

1. Kojima, Y., Usuki, A., Kawasumi, M., Okada, A., Kurauchi, T.T. and Kamigaito. O. J. (1993). Synthesis of nylon 6-clay hybrid by montmorillonite intercalated with €-caprolactam. Journal of polymer science, part A, polymer chemistry, 31(4), 983-986.

2. Kawasumi, M. (2004). The discovery of polymer clay hybrids. Journal of polymer science, part A, polymer chemistry, 42 (4), 819-824.
3. Okada, A. and Usuki, A. (2006). Twenty years of olymer-clay nanocomposites. Macromolecular materials and engineering, 291 (12), 1449-1476.

4. Pillin, I., Montrelay, N. and Grohens, Y. (2006). Thermomechanical characterization of plasticized PLA: Is the miscibility the only significant factor? Polymer, 47 (13), 4676-4682.

5. Rossi, S., Luckham, P.F. and Tadros, T.F. (2003). Influence of non-ionic polymers on the rheological behaviour of na -montmorillonite clay suspensions. part II. homopolymer ethyleneoxide and polypropylene oxide-polyethylene oxide ABA copolymers. Colloids and surfaces A: Physicochemical and engineering aspects, 215 (1-3), 1-10.

6. Chen, J. S., Poliks, M.D., Ober,C.K., Zhang,Y., Wiesner, U., and Giannelis, E. (2002). Study of the interlayer expansion mechanism and thermal-mechanical properties of surface-initiated epoxy nanocomposites. Polymer, $\mathbf{4 3}$ (18), 4895-4904

7. Ray,S.S. and Okamoto, M. (2003). Polymer/layered silicate nanocomposites: A review from preparation to processing. Progress in polymer science, 28 (11), 15391641.

8. Equilibrium relative humidty at http://www.omega.com/temperature/z/pdf/z103.pdf

9. Chen, B. and Evans, J. R. G. (2005). X-ray diffraction studies and phase volume determinations in poly (ethylene glycol)-montmorillonite nanocomposites. Polymer international, 54 (5), 807-813.

10. Chen, B. and Evans, J.R.G (2005). On the thermodynamic driving force for polymer intercalation in smectite clays. Philosophical magazine,85(14),15191538 